\title{
Les Controvèrsies Sòcio-Científiques com a contextos d'aprenentatge i comunicació a l'aula. Anàlisi crítica de la informació i habilitats comunicatives
}

\begin{abstract}
Laura Farró (Ifarro@xtec.cat) Centre de Recursos Pedagògics Específics de Suport a la Innovació i la Recerca Educativa (CESIRE), Departament d'Ensenyament de la Generalitat de Catalunya.

Sílvia Lope (slope@xtec.cat) Centre de Recursos Pedagògics Específics de Suport a la Innovació $i$ la Recerca Educativa (CESIRE), Departament d'Ensenyament de la Generalitat de Catalunya.

Anna Marbà (anna.marba@uab.cat) Grup LIEC, Departament de Didàctica de la Matemàtica i les Ciències Experimentals, Universitat Autònoma de Barcelona.

Begonya Oliveras (bolivera@xtec.cat) Institut Obert de Catalunya (IOC).
\end{abstract}

La formulació de propostes de treball amb controvèrsies sòcio-científiques (o CSC) implica treballar tres eixos fonamentals: la definició i proposta de dilemes rellevants, $i$ el treball explícit de la lectura crítica $i$ altres habilitats comunicatives com el debat. Es proposen criteris $i$ estratègies de treball en aquestes tres línies $i$ un marc general de tipus de CSC.

Paraules clau: Controvèrsies, RRI, Debat, Lectura Crítica, Dilema.

Constructing learning activities with Socio-Scientific Issues implies the development of three key axes: the proposal of relevant dilemmas on the one side, and the explicit work on critical reading and communicative skills (as debating) on the other side. We propose in this article methodologic frames and strategies on these three axes and a general frame of the kinds of Socio-Scientifis Issues.

Keywords: Socio-Scientific Issues, RRI, Debate, Critical Reading, Dilemma.

\section{INTRODUCCIÓ}

Les controvèrsies Sòcio-científiques (CSC) són actualment un recurs amb molt de potencial per afavorir l'aprenentatge de les ciències: són contextos d'aprenentatge situat, exigeixen un grau de raonament moral o d'avaluació ètica, requereixen del posicionament de l'alumnat davant de la qüestió tractada així com de la seva participació en el debat i l'argumentació, inclouen desacords dins la comunitat científica sobre la validesa d'afirmacions relaciones amb la ciència, etc.

Es defineixen com a dilemes socials que incideixen $\mathrm{o}$ tenen implicacions en els àmbits científics (Domènech, 2014). Les CSC poden estar més relacionades amb aspectes socioeconòmics, polítics, o ètics, etc. que generen diferents corrents de pensament dins la societat civil (ja hi ha consens entre bona part de la comunitat científica però en canvi, la controvèrsia la té la societat civil, com per exemple, el cas de la investigació en cèl-lules mare) o bé ser pròpiament científiques, com passa en aquells temes pels quals la comunitat científica encara no ha arribat a un consens majoritari, bé perquè hi ha diferents maneres d'explicar-se el què està passant, o bé perquè encara no hi ha prou dades o fins i tot, capacitat de generar-les per posicionar-se (com passa per exemple, el les incidències a llarg termini de certes ones 0 dels aliments modificats 
genèticament). Segurament, cal pensar també en controvèrsies pseudocientífiques, on es presenten divergències des del punt de vista científica, quan la comunitat científica té una posició ben definida, com podria ser el cas de les vacunes.

A més d'oferir un context rellevant per a entendre i treballar els coneixements científics (Zeidler i Nicols, 2009), les CSC ens permeten discutir aspectes de naturalesa de la ciència, promovent que l'alumne es construeixi una visió més real i vàlida de què és la ciència: incerta, evolutiva, discrepant, augmentativa, imaginativa, etc. i els valors i objectius socioeconòmics i polítics que hi poden haver darrera de les investigacions.

En aquest sentit, la valoració crítica i les habilitats comunicatives de construcció del coneixement són dos eixos fonamentals del treball amb CSC: cal dialogar, argumentar, justificar decisions, etc.

Per una banda, l'accés generalitzat a la informació a través d'Internet i dels mitjans de comunicació, requereix formar ciutadans crítics, capaços de posicionar-se davant de problemàtiques que sovint tenen una fonamentació científica (canvi climàtic, energies alternatives, graffitis, aliments transgènics...). Aquest posicionament crític ha d'anar lligat a la informació que llegim, però també als productes que comprem, sovint vestits per una informació poc fiable.

D'altra banda, els models de debat o conversa que els alumnes tenen a través de la televisió o d'altres canals audiovisuals s'aparten, moltes vegades, dels requisits que necessita tota bona conversa o debat per esdevenir constructiu i productiu. Sovint, per no dir sempre, aquestes activitats discursives es desenvolupen en un clima de manca de respecte entre els participants i d'un profund desconeixement del tema, allunyant-se, així, del principi de cooperació formulat pel filòsof H.P. Grice (1975), segons el qual els parlants han de construir conjuntament l'intercanvi comunicatiu col-laborant, a mesura que avança la conversa, de la manera més adequada. Per aquest motiu, cal ensenyar explícitament a l'alumnat les eines necessàries per poder intervenir en debats, converses o controvèrsies, participant, així, activament en la construcció conjunta de coneixement.

\section{RECURSOS I PROPOSTES}

\section{L'elecció d'una controvèrsia a partir de la qual construir coneixement científic}

Per promoure la implicació i comunicació a l'aula al voltant d'una controvèrsia, és fonamental una bona elecció del tema o dilema, que cal que tingui en compte els diferents aspectes de la Figura 1 (elaborats en el marc del grup LIEC).

Un cop definida la controvèrsia, cal articular els coneixements científics al seu voltant per a elaborar l'activitat didàctica. En aquest sentit poden ser d'utilitat diversos recursos pensats com a activitats de curta durada, que permeten teixir llaços a nous coneixements científics (veure Figura 2).

\section{Criteris per caracteritzar una CSC}

1) Es tracta d'un tema social, esdeveniment $o$ activitat, amb freqüència un dilema, que té a la seva base nocions científiques.

2) Reflecteix la interdependència ciència-societat.

3) Hi ha discrepàncies entre els diferents agents que hi estan implicats.

4) Apareix freqüentment als mitjans de comunicació.

5) És una controvèrsia local o global sobre la que encara no existeix una resposta única i definitiva. Reflecteix la naturalesa i els procediments científics.

6) Els estudiants hauran de tractar aquesta problemàtica al llarg de la seva vida.

7) Està vinculada als coneixements i competències científiques que s'han de treballar amb els estudiants.

8) Permet que els estudiants puguin avaluar, estructurar 0 aplicar coneixements i competències científiques.

Figura 1. Criteris per a escollir/elaborar una CSC. Domènech (2014), Domènech i Márquez (2014). 


\begin{tabular}{|l|l|}
\hline $\begin{array}{l}\text { Play Decide } \\
\text { http://www.playdecide.eu/ }\end{array}$ & $\begin{array}{l}\text { Joc de discussió per parlar de manera simple i efectiva de temes controvertits. } \\
\text { Presenta la diversitat d'opinions que hi pot haver a la societat donant veu als implicats. Es } \\
\text { dóna molta importància a la reflexió personal en cada pas del joc (per exemple, es demana } \\
\text { que es verbalitzi el per què cada participant ha escollit un dels rols presentats, etc.). El joc } \\
\text { també proporciona la informació científica necessària per entendre la part més tècnica del } \\
\text { dilema. Al final, cal arribar a un consens i presentar una possible llei al respecte. }\end{array}$ \\
\hline $\begin{array}{l}\text { Pedagogie in Action. } \\
\text { Socioscientific issues-based instruction. } \\
\text { http://serc.carleton.edu/sp/library/issues/what.html }\end{array}$ & $\begin{array}{l}\text { Web amb recursos teòrics i pràctics. Al web hi trobareu una bona fonamentació teòrica de } \\
\text { perquè cal treballar amb dilemes sociocientífics a l'aula (així com d'altres temes). }\end{array}$ \\
\hline $\begin{array}{l}\text { Engage. } \\
\text { Nuevas ideas aplicadas al currículum } \\
\text { http://www.engagingscience.eu/es/ }\end{array}$ & $\begin{array}{l}\text { Web amb activitats relacionades amb diferents dilemes SC. Les activitats es presenten en } \\
\text { funció dels continguts tranversals i científics curriculars de cada curs de l'ESO. Proporcionen } \\
\text { diferents recursos per cada activitat. }\end{array}$ \\
\hline $\begin{array}{l}\text { PreSSES } \\
\text { http://www.ssieurope.net/ }\end{array}$ & $\begin{array}{l}\text { Material pel professorat per ajudar-lo a treballar amb les connexions entre ciència i vida } \\
\text { quotidiana. A més de treballar pròpiament les CSC proposa reflexionar amb els alumnes el } \\
\text { fet de treballar amb aquests contextos. }\end{array}$ \\
\hline $\begin{array}{l}\text { Figura 2. Selecció de propostes d'activitats breus que parteixen d'una controvèrsia que es pot vincular al } \\
\text { currículum }\end{array}$
\end{tabular}

\section{L’articulació de dinàmiques de lectura crítica}

Per poder analitzar, interpretar i criticar un text (article de diari, publicitat,...) amb contingut científic coma ciutadans crítics els estudiants han de poder apropar-se als escrits amb referents científics. El problema és que el model 0 models teòrics associats a la lectura d'un text amb contingut científic o a l'anàlisi de la informació dels productes són generalment implícits, per tant, caldrà ajudar a l'alumnat a trobar aquesta connexió, perquè poc a poc ho puguin fer de manera autònoma. Serà, per tant, necessari dissenyar estratègies de lectura $\mathrm{i}$ anàlisi de la informació que ajudin a activar el model científic implícit (Oliveras i Sanmartí, 2008).

\section{1) Llegir críticament textos de diari mitjancant el treball cooperatiu}

La comprensió crítica de textos comporta assumir que el discurs no reflecteix la realitat amb objectivitat, sinó que ofereix una mirada particular i contextualizada. Llegir significa comprendre, interpretar, analitzar i criticar els texts (Cassany, 2006). La lectura depèn dels coneixements previs del lector i requereix contextualitzar i inferir les intencions de l'autor i la construcció activa de nous coneixements (Yore, Craig i Maguire, 1998). Els lectors poden posicionar-se epistemològicament de diferents maneres respecte a un text (Olson, 1994):

1) Adoptant una posició dominant i permetent que les seves idees prèvies condicionin la informació del text.

2) Permetent que el text condicioni les seves idees prèvies i s'interpreti en contra d'elles.

3) Adoptant una postura crítica i iniciar una negociació interactiva entre el text i les seves creences o opinions per aconseguir una interpretació que sigui el més consistent $\mathrm{i}$ completa possible.

Aquesta darrera és la posició que ens interessa que l'alumnat adquireixi. Les activitats es dissenyen a partir de textos de diari que continguin notícies controvertides i d'actualitat i relacionades amb el currículum, que prèviament cal seleccionar.

\section{Qüestionari de lectura crítica}

Per cada article que es treballi a l'aula proposem una activitat de lectura acompanyada que permetrà treballar el text de manera crítica. Aquesta activitat pot durar 1 o 2 sessions.

Les activitats que plantegem es basen en la seqüenciació de preguntes que ajuden a l'anàlisi i reflexió crítica del text. Nosaltres fem una proposta que parteix del qüestionari C.R.I.T.I.C. proposat per Bartz (2002) i de les aportacions del grup d'investigació LIEC (Llenguatge i Ensenyament de les Ciències) de la UAB. Aquest qüestionari promou que l'alumnat identifiqui les principals afirmacions del discurs $\mathrm{i}$ els interessos que mouen a l'autor/a a construir-lo i el punt de vista que adopta, que valori la solidesa, fiabilitat i validesa de les evidències $\mathrm{i}$ arguments aportats $\mathrm{i}$ que detecti incoherències, imprecisions, errors i/o contradiccions, aspectes necessaris per a una lectura significativa i crítica. 


\begin{tabular}{|c|c|}
\hline Elements de lectura crítica de Ciències & Exemples de preguntes \\
\hline 1. Identificar les idees principals del text & $\begin{array}{l}\text {-Quin problema s'exposa en el text? Quina és la idea principal? } \\
\text {-Amb quins continguts científics pot estar relacionat?. }\end{array}$ \\
\hline 2. Identificar el propòsit de l' autor/a & $\begin{array}{l}\text {-Qui ha escrit aquest document? } \\
\text {-Per què el deu haver escrit? }\end{array}$ \\
\hline 3. Identificar les suposicions i el punt de vista de l' autor/a & $\begin{array}{l}\text {-Quin és el punt de vista de l' autor/a? } \\
\text {-Quines suposicions fa l'autor/a en el text? }\end{array}$ \\
\hline 4. Formular una pregunta científica a la que dóna resposta l' & -Es podria fer una prova o experiment per comprovar la credibilitat de \\
\hline $\begin{array}{l}\text { Dissenyar un experiment científic per comprovar la informació } \\
\text { del text }\end{array}$ & - Quina pregunta es faria un científic per investigar aquest problema? \\
\hline 5. Identificar dades i evidències del text & $\begin{array}{l}\text { - Hi ha dades, arguments o evidències científiques en el text que justifiquen } \\
\text { l'afirmació inicial?. Escriu-les }\end{array}$ \\
\hline 6. Treure conclusions inferint-les a partir de proves & - Escriu un text argumentatiu validant o refutant la informació científica del text. \\
\hline
\end{tabular}

Figura 3. Elements de la lectura crítica de Ciències (Oliveras 2013).

En el disseny de l'activitat també s'han de tenir en compte les tres fases del procés lector: fase prèvia (activació d'idees prèvies i formulació de les hipòtesis inicials), durant la lectura (regulació del procés de lectura mitjançant el qüestionari d'elements de lectura crítica) i després de la lectura (cerca d'informació a Internet per contrastar la informació i avaluació de la informació redactant-la en un text augmentatiu final). En totes les activitats es treballa de manera cooperativa, a excepció del text argumentatiu final que és individual. El treball en grup afavoreix la comprensió i anàlisi crítica de la informació (Colomer, 2002; Márquez i Prat, 2005; Oliveras i Sanmartí, 2008).

\section{Avaluació de les activitats}

A partir d'una rúbrica es pot avaluar la lectura crítica del text.

Aquestes estratègies s'han aplicat a diferents instituts de Catalunya, amb molt bons resultats(Oliveras, Márquez i Sanmartí, 2013; 2014). Hi ha disponibles diverses activitats seguint aquesta pauta a la web d'Innovació del Departament d'Ensenyament [1] i la pàgina del Ministerio de Educación, Cultura y Deporte [2].

\section{2) Analitzar críticament productes comercials i anuncis publicitaris}

Els miniops [3] són cursos de contingut obert de curta durada (15-20 hores) vinculats a temes actuals. S'ofereixen des de l'IOC dins de categories (xarxes, coses i món).

El Miniop «Química a la vida quotidiana» [4] està dissenyat amb l'objectiu d'ajudar a l'alumnat a la presa de decisions en la compra de productes quotidians (aigua, productes neteja, detergents) a partir de l'anàlisi de les etiquetes i a la vegada reflexionar críticament sobre la seva publicitat.

La seqüència és la següent: 1) Es donen breus fonaments científics per poder analitzar els productes a treballar; 2) Es planteja una pregunta rellevant respecte el producte a comprar; 3) Es donen criteris d'anàlisi per reflexionar, 4) Es debat en un fòrum de participació o es fa participar activament a través d'un experiment.

Aquest curs s'ha aplicat amb estudiants de I'Institut Obert de Catalunya que volen acreditar per l'obtenció del Graduat Escolar GES.

Les actituds i habilitats comunicatives en el debat sociocientífic a l'aula

Un debat o conversa per passar de conversa informal a conversa exploratòria [5] en la que es creï coneixement, ha de seguir unes regles concretes, i demana un seguit de coneixements, actituds i habilitats concretes.

Els coneixements necessaris sobre el tema. En primer $\| \mathrm{oc}$, caldrà que el docent proporcioni fonts d'informació fiables, planificant sessions de recerca i validació d'aquesta informació, entre d'altres activitats. Caldrà, però, també dotar l'alumnat dels coneixements necessaris relacionats amb el gènere textual del debat i compartir amb ells les característiques i les regles per portar-lo a terme 


\begin{tabular}{|c|c|c|c|c|c|}
\hline & 5 & 4 & 3 & 2 & 1 \\
\hline Idees principals & $\begin{array}{l}\text { Expressen amb les seves } \\
\text { pròpies paraules la informació } \\
\text { més important de manera } \\
\text { entenedora. Identifiquen totes } \\
\text { les idees i conceptes claus } \\
\text { que s'usen d'una manera } \\
\text { entenedora }\end{array}$ & $\begin{array}{l}\text { Ex Expressen amb les } \\
\text { seves pròpies paraules la } \\
\text { informació més important. } \\
\text { Identifiquen algunes de les } \\
\text { idees i conceptes claus que } \\
\text { s'usen d'una manera } \\
\text { entenedora. }\end{array}$ & $\begin{array}{l}\text { Fan referència a més } \\
\text { d'una idea o concepte } \\
\text { clau. }\end{array}$ & $\begin{array}{l}\text { Només identifiquen } \\
\text { una de les idees o } \\
\text { conceptes claus }\end{array}$ & $\begin{array}{l}\text { Citen informació no } \\
\text { rellevant o no } \\
\text { reelaboren la } \\
\text { informació. }\end{array}$ \\
\hline Propòsit Autor/a & $\begin{array}{l}\text { Comuniquen bé el propòsit } \\
\text { que creuen que té l'autor/a. } \\
\text { S'adonen que l'autor/a a } \\
\text { més d'informar té d'altres } \\
\text { intencions (crear polèmica....). }\end{array}$ & $\begin{array}{l}\text { Identifiquen el propòsit de } \\
\text { l'autorla però de manera } \\
\text { poc precisa ja sigui perquè } \\
\text { no redacten bé o perquè no } \\
\text { concreten prou. }\end{array}$ & $\begin{array}{l}\text { Suposen que les notícies } \\
\text { només són per informar } \\
\text { d' una manera neutra i } \\
\text { imparcial }\end{array}$ & $\begin{array}{l}\text { La informació que } \\
\text { expressen no es pot } \\
\text { inferir del text }\end{array}$ & $\begin{array}{l}\text { Citen informació } \\
\text { irrellevant }\end{array}$ \\
\hline $\begin{array}{l}\text { Suposicions i punt } \\
\text { vista autor/ }\end{array}$ & $\begin{array}{l}\text { Fan suposicions raonables i } \\
\text { identifiquen i justifiquen el } \\
\text { punt de vista de l'autor/a a } \\
\text { partir del text. }\end{array}$ & $\begin{array}{l}\text { Fan suposicions raonables, } \\
\text { identificant el punt de vista } \\
\text { de l'autor/a però no el } \\
\text { justifiquen. }\end{array}$ & $\begin{array}{l}\text { Citen frases textuals del } \\
\text { text sense inferir el punt } \\
\text { de vista del autor/a. }\end{array}$ & $\begin{array}{l}\text { Fan suposicions no } \\
\text { raonables en funció } \\
\text { d'evidències i no } \\
\text { identifiquen el punt } \\
\text { de vista de l'autor/a }\end{array}$ & $\begin{array}{l}\text { No contesten o citen } \\
\text { informació irrellevant } \\
\text { o no identifiquen el } \\
\text { punt de vista de } \\
\text { l'autor/a. }\end{array}$ \\
\hline $\begin{array}{l}\text { Pregunta científica } \\
\text { o disseny } \\
\text { experiment científic }\end{array}$ & $\begin{array}{l}\text { Formulen preguntes } \\
\text { fonamentades i importants } \\
\text { des de la ciència, analitzant } \\
\text { totes les variables a } \\
\text { considerar, o realitzarien un } \\
\text { experiment per comprovar-ho } \\
\text { basat en totes les variables. }\end{array}$ & $\begin{array}{l}\text { Formulen preguntes } \\
\text { fonamentades i importants } \\
\text { des de la ciència, analitzant } \\
\text { només una de les } \\
\text { variables, o realitzarien un } \\
\text { experiment per comprovar- } \\
\text { ho basat en una de les } \\
\text { variables. }\end{array}$ & $\begin{array}{l}\text { Es pregunten qüestions } \\
\text { a les que no respon el } \\
\text { text o realitzen } \\
\text { experiments dirigits } \\
\text { únicament a entendre el } \\
\text { perquè del problema. }\end{array}$ & $\begin{array}{l}\text { Es plantegen la } \\
\text { pregunta sense } \\
\text { concrecions o } \\
\text { realitzarien } \\
\text { experiments massa } \\
\text { generals. }\end{array}$ & $\begin{array}{l}\text { Plantegen preguntes } \\
\text { poc coherents o } \\
\text { experiments } \\
\text { irrellevants }\end{array}$ \\
\hline $\begin{array}{l}\text { Identificació de } \\
\text { dades i evidències }\end{array}$ & $\begin{array}{l}\text { Distingeixen entre fets, } \\
\text { arguments científics i opinions } \\
\text { del text. Treuen conclusions } \\
\text { tenint en compte la informació } \\
\text { de què disposen i per un } \\
\text { raonament sensat demostren } \\
\text { capacitat per analitzar i } \\
\text { avaluar la informació } \\
\text { objectivament. }\end{array}$ & $\begin{array}{l}\text { Treuen conclusions } \\
\text { fonamentades a partir } \\
\text { d'informació aportada pel } \\
\text { text (fets, dades, evidències } \\
\text {...), sense distingir el tipus } \\
\text { de font (fet, opinió, } \\
\text { argument científic...). }\end{array}$ & $\begin{array}{l}\text { Fan referència a si el text } \\
\text { dóna evidències o no, o } \\
\text { a si les informacions que } \\
\text { aporta tenen validesa } \\
\text { cientifica, sense més } \\
\text { explicacions o donant } \\
\text { arguments poc. }\end{array}$ & $\begin{array}{l}\text { Citen informacions } \\
\text { del text amb un } \\
\text { raonament no } \\
\text { elaborat i imprecís o } \\
\text { bé treuen } \\
\text { conclusions } \\
\text { basades en } \\
\text { informacions del } \\
\text { text no rellevant i no } \\
\text { es refereixen a si } \\
\text { són evidències o no. }\end{array}$ & $\begin{array}{l}\text { Validen la informació } \\
\text { per confiança amb el } \\
\text { diari (no jutgen la } \\
\text { credibilitat de la font) } \\
\text { o perquè creuen que } \\
\text { l'autor/a s'ha } \\
\text { informat. }\end{array}$ \\
\hline $\begin{array}{l}\text { Argumentació de } \\
\text { conclusions }\end{array}$ & $\begin{array}{l}\text { Confronten la informació del } \\
\text { text amb els coneixements } \\
\text { científics, mostrant capacitat } \\
\text { per argumentar de forma } \\
\text { fonamentada acords i } \\
\text { desacords }\end{array}$ & $\begin{array}{l}\text { Confronten la informació } \\
\text { del text amb els seus } \\
\text { coneixements científics i } \\
\text { mostren acords o } \\
\text { desacords raonables sense } \\
\text { fonamentar-los } \\
\text { explícitament. }\end{array}$ & $\begin{array}{l}\text { Activen els seus } \\
\text { coneixements de ciència } \\
\text { i mostren capacitat per } \\
\text { argumentar acords i } \\
\text { desacords, tot i que no } \\
\text { confronten els seus } \\
\text { coneixements amb la } \\
\text { informació del text. }\end{array}$ & $\begin{array}{l}\text { Arriben a } \\
\text { conclusions a partir } \\
\text { de coneixements } \\
\text { quotidians sense } \\
\text { activar els } \\
\text { coneixements } \\
\text { cientifics. }\end{array}$ & $\begin{array}{l}\text { Citen arguments } \\
\text { irrellevants }\end{array}$ \\
\hline
\end{tabular}


Les actituds per a la competència discursiva. L'objectiu d'una conversa en general, i especialment a l'aula, és aconseguir una comprensió conjunta, arribar a acords, i això només serà possible, si es té la voluntat $i$ l'actitud d'explorar i comprendre el discurs dels altres, en un clima de cordialitat i confiança. Cal compartir explícitament amb l'alumnat la necessitat de crear aquest clima. Les activitats cinèsiques que exploren la comunicació no verbal poden ser una bona estratègia per comprendre $\mathrm{i}$ interioritzar aquestes actituds: demanar als alumnes que representin amb les mans com un joc de forces contràries l'oposició entre dos arguments, o explorar conjuntament la imatge que conté un cub del que cada participant veu només una part, els portarà a percebre que cada persona pot tenir perspectives diferents sobre una mateixa temàtica o situació, i que la visió multifocal que proporciona la interacció conversacional entre els membres d'un grup sempre aportarà una mirada més àmplia, rica i complexa que la mirada individual; que cal avançar en la percepció que les discrepàncies són una oportunitat, i no una amenaça, per aprendre i completar les diferents cares d'un mateix prisma. Incorporar el treball de la presa de consciència de la complexitat permetrà als aprenents a anar teixint un entramat de noves actituds, necessàries per intervenir en debats $i$ controvèrsies per comprendre els fenòmens del nostre món complex, canviant $\mathrm{i}$ incert.

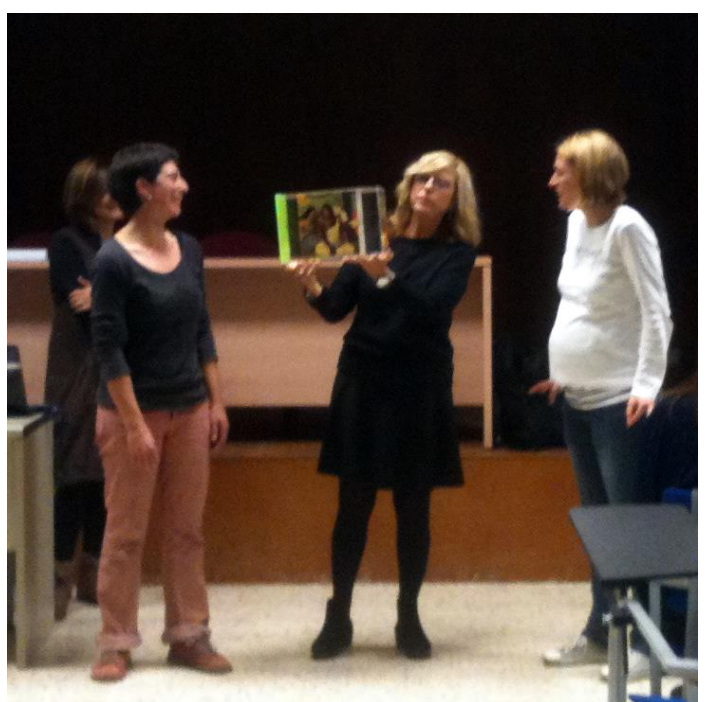

Figura 5. Imatge d'activitat on dos participants situats a costats oposats del cub veuen diferents parts de la imatge i intenten arribar acords sobre el contingut, adonant-se de la riquesa que comporta la conversa exploratòria constructiva.
Les habilitats comunicatives: escoltar activament i conversar explorant.

En relació a l'escolta els caldrà aprendre a desxifrar els diferents missatges que s'expressen de manera simultània en qualsevol conversa. Ens referim a tot allò que no es diu amb paraules però que s'infereix del comportament, els tons i el llenguatge no verbal dels interlocutors. Mantenir el contacte visual, adoptar una posició corporal no intimidadora, somriure, assentir, no interrompre quan l'altre parla, repetir amb paraules diferents, és a dir reformular, allò que l'emissor està dient per verificar-ne la comprensió. En definitiva, escoltar activament voldrà dir aprendre a seguir el discurs mental de l'altre donant mostres amb el llenguatge verbal i no verbal.

En relació a la conversa exploratòria han d'aprendre a respectar torns de paraula, implicar-se de manera crítica tot aportant idees, ser conscients que la intervenció d'un es construeix en funció de la resposta de l'altre. També a seleccionar la informació perquè aquesta ha de ser rellevant i de qualitat. Han d'aprendre a qüestionar propostes $\mathrm{i}$ a fer contrapropostes, oferir raons i alternatives perquè, en definitiva, es busca arribar a acords per progressar conjuntament.

Així, doncs, la conversa exploratòria es basa en l'intent d'establir prioritats, arribar a punts d'acord, reduir la discrepància sense perdre el discurs crític, en definitiva ens porta a interpensar per construir i compartir coneixement. Amb paraules de N. Mercer (1997) direm que "La conversa exploratòria és un model de diàleg en la qual els participants no s'ocupen principalment de protegir els seus interessos i de mantenir les seves identitats separades, sinó que intenten aconseguir una comprensió conjunta d'una manera racional".

Totes aquestes habilitats no les podem llegir com a simples normes de cortesia, sinó com a eines imprescindibles per a un debat constructiu que necessiten ser interioritzades i apreses. Podem guiar les intervencions d'una conversa exploratòria proposant a l'alumnat l'ús d'unes etiquetes lingüístiques, a mode de baralla de cartes, que hauran d'utilitzar durant tot un debat. Són una guia per anar interioritzant els continguts, les habilitats i els coneixements que demana la participació competent en un debat, controvèrsia o dilema. Així, aquestes etiquetes lingüístiques els porten a respectar les opinions, mostrar acord, desacord, presentar noves idees o nous arguments, a preguntar 
quan no els ha quedat clara alguna cosa, demanar més informació sobre el tema, etc... i apropiar-se de les estratègies conversacionals que els permetran intervenir i regular amb èxit un debat a l'aula i fora de l'aula.

\section{ETIQUETES EXPLORATÒRIES}

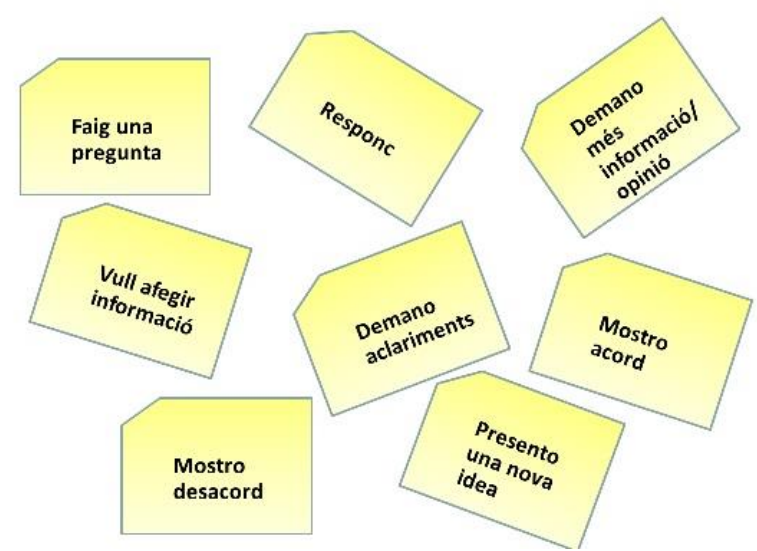

Figura 6. L'ús d'etiquetes o targetes que l'alumne ha de brandar en fer una intervenció ajuda a pautar el debat i considerar els tipus d'intervencions que el configuren.

\section{CONCLUSIONS I PERSPECTIVES}

Transformar la manera que tenim de fer classes de ciències per aconseguir que més alumnes siguin capaços d'aplicar allò après a classe per tenir una opinió més científica envers els problemes de l'entorn i promoure que puguin prendre decisions basades en criteris científics, és un objectiu que fa molt de temps que perseguim. Les CSC són un recurs que ens facilita enormement el pensar en activitats que ajudin a l'alumne a pensar, fer i comunicar ciència, a treballar els valors, a ajudarlos a desenvolupar un pensament reflexiu, a importar un model d'aprenentatge més semblant a la societat del segle XXI on viuen, etc.

Aquestes propostes, a més de treballar l'anàlisi crítica de la informació fomenten habilitats cognitivo-lingüístiques com l'argumentació (Jorba, Gómez i Prat, 1998) i el treball en equip, la coavaluació i regulació de l'aprenentatge (Oliveras, Márquez i Sanmartí, 2008). Les CSC són també un entorn en el que mitjançant el debat -amb paraules de Edwards i Mercer (1988)- s'expressa, es reestructura i es construeix coneixement, habilitats que esdevindran aprenentatges de llarga durada.

Des de perspectives complementàries sobre les CSC i la RRI, el lector pot trobar d'interès també materials d'altres articles publicats en aquest mateix número de la revista Ciències (AlcarazDomínguez et al, 2015, Domènech-Casal, Marchán i Vergara, 2015) com a part de les Jornades sobre Controvèrsies Sòcio-Científiques i Recerca i Innovació Responsables \#cscri15 (DomènechCasal i Lope, 2015).

\section{AGRAIIMENTS}

Aquest article recull el contingut de tres ponències presentades pels autors a les "Jornades de Controvèrsia Sòcio-Científica i Recerca $i$ Innovació Responsables. Ciències per a qüestionar i canviar el món. Pensar, comprendre, decidir." (https://cienciaicontroversia.wordpress.com/) que es van celebrar els dies 21-X, 4-XI i 25 XI de 2015 al CESIRE de Barcelona (Drassanes) del Departament d'Ensenyament de la Generalitat de Catalunya. Agraïm la col•laboració de l'alumnat i professorat que ha participat en les diferents recerques.

Part de les eines $\mathrm{i}$ experiències recollides en aquest article s'emmarquen en la reflexió metodològica del grup LIEC (Llenguatge i Ensenyament de les Ciències) de la Universitat Autònoma de Barcelona -grup de recerca consolidat (referència 2014SGR1492) per AGAUR (Agència de Gestió d'Ajuts Universitaris i de Recerca) finançat per el Ministerio de Educación y Ciencia (referència EDU-2012-38022-C02-02.

\section{BIBLIOGRAFIA}

ALCARAZ-DOMÍNGUEZ, S., BARAJAS, M., MALAGRIDA, R., PÉREZ, F. (2015). Els projectes Europeus Engaging Science, Xplore Health, RRI Tools i Scientix. Finestres a la formació i la participació en comunitats docents per al treball amb Controvèrsies $i$ Recerca $i$ Innovació Responsables. Revista Ciències (aquest mateix número).

BARTZ, W.R. (2002). Teaching Skepticism via the CRITIC Acronym and the Skeptical Inquirer. The Skeptical Inquirer, 26(5), pp.42-44.

CASSANY, D. (2006). Tras las líneas: sobre la lectura contemporánea. Barcelona: Anagrama.

DOMÈNECH, A. (2014). L'ús de les controvèrsies sociocientífiques per promoure la competència científica a l'educació secundària: el cas de la medicalització $i$ el TDA. Tesi Doctoral. [http://www.tdx.cat/handle/10803/283516]

DOMĖNECH-CASAL, J., MARCHÁN, I., VERGARA, E. (2015). Experiències d'aula amb el treball amb Controvèrsies Sòcio-Científiques. 
Educació per al Desenvolupament i la Salut, Pseudociències $i$ eines per a l'avaluació d'activitats. Revista Ciències (aquest mateix número).

DOMĖNECH-CASAL, J., LOPE, S. (2015). Les Jornades de Controvèrsia Sòcio-Científica $i$ Recerca i Innovació Responsables. Ciències per a qüestionar $i$ canviar el món. Pensar, comprendre, decidir. Revista Ciències (aquest mateix número).

MÁRQUEZ, C.; PRAT, A. (eds.) (2010). Competència científica i lectora a secundària. Barcelona: Rosa Sensat.

MERCER, N. Palabras y mentes. Cómo usamos el lenguaje para pensar juntos. Ed. Paidós. Barcelona, 2001.

MERCER, N. La construcción guiada del conocimiento. Ed. Paidós. Barcelona, 1997.

MERCER, N., EDWARDS, D. El conocimiento compartido, El desarrollo de la comprensión en el aula. Ed. Paidos, Barcelona 1988

OLIVERAS, B.; SANMARTÍ, N. (2009). La lectura como medio para desarrollar el pensamiento crítico. Educación Química, 20 (1), 233-245.

OLIVERAS, B.; MÁRQUEZ, C.; SANMARTÍ, N. (2013). The Use of Newspaper Articles as a Tool To Develop Critical Thinking in Science Classes. International Journal of Science Education, 35 (6), 885-905.
OLIVERAS, B.; MÁRQUEZ, C.; SANMARTÍ, N. (2014). Students' Attitudes to Information in the Press: Critical Reading of a Newspaper Article With Scientific Content. Research in Science Education. 44 (4), 603-626.

OLSON, D. R. (1994). The world on paper. Cambridge: Cambridge University Press.

YORE, L.D., CRAIG, M.T, MAGUIRE, T.O., Index of science reading awareness: An interactiveconstructive model, text verification, and grades 4-8 results. Journal of Research in Science Teaching, 35, 27-51, 1998.

ZEIDLER, D. L., NICOLS, B. H. N. (2009). Socioscientific Issues: Theory and Practice. Journal of Elementary Science Education, 21 (2). 49-58.

[1] Disponible a :

http://www.xtec.cat/sgfp/llicencies/200809/memorie s/1891m.pdf

[2] Disponible a:

http://leer.es/recursos/hablar/

[3] Disponible a:

http://miniops.ioc.cat/miniops.html

[4] Disponible a.

http://miniops.ioc.cat/11/index.html

[5] Disponible a:

http://ateneu.xtec.cat/wikiform/wikiexport/_media/fic /cco/cco03/fase_3/bloc_2/conversaexploratoria. $\mathrm{ppt}$ 